\title{
STUDI KAJIAN PERILAKU BANGUNAN GEDUNG KAYU BERTINGKAT RENDAH DENGAN ANALISIS TIME HISTORY
}

\author{
Bernardinus Herbudiman ${ }^{1}$, Syafarina Nurmah Rialita ${ }^{2}$, Yosafat Aji Pranata ${ }^{3}$ \\ ${ }^{1}$ Dosen, Program Studi Teknik Sipil, FTSP, Institut Teknologi Nasional Bandung \\ ${ }^{2}$ Alumnus, Program Studi Teknik Sipil, FTSP, Institut Teknologi Nasional Bandung \\ ${ }^{3}$ Dosen, Program Studi Teknik Sipil, FT, Universitas Kristen Maranatha, Bandung \\ E-mail: herbudiman@itenas.ac.id, syafarinanr@gmail.com, yosafat.ap@gmail.com
}

\begin{abstract}
ABSTRAK
Hotel dirancang menyerupai rumah panggung yang merupakan rumah khas bagi masyarakat Bugis-Makassar. Material struktur yang dipilih adalah kayu Libung karena ringan, dan fleksibel. Struktur bangunan dimodelkan menjadi Model 1 (konvensional) dan Model 2 (link). Beban gempa menggunakan analisis riwayat waktu. Analisis riwayat waktu dengan tiga beban gempa referensi yang diskalakan dapat digunakan untuk memberikan gambaran gaya lateral yang bekerja pada bangunan.Struktur kayu tersebut dievaluasi terhadap parameter gaya geser dasar, simpangan antar lantai, dan taraf kinerja struktur. Taraf kinerja struktur mengacu pada ATC-40 yang ditentukan dari rasio maximum total roof displacement terhadap ketinggian struktur. Model struktur dengan link memiliki nilai periode lebih besar daripada struktur model konvensional, karena memiliki kekakuan sambungan balok-kolom yang lebih rendah. Model struktur dengan link memiliki gaya geser dasar akibat gempa lebih rendah, namun simpangannya lebih besar. Nilai rasio maximum drift terhadap tinggi total struktur akibat empat gempa yang ditinjau memiliki nilai rasio lebih kecil 0,010 sehingga taraf kinerja struktur adalah immediate occupancy.
\end{abstract}

Kata Kunci: link, analisis riwayat waktu, bangunan kayu, kinerja struktur

\begin{abstract}
The hotel was designed to be similar with Bugis-Makassar tradisional house. Libung wood is choosed as structural material due to its lightweight and flexible. Building structures is modelled as Model 1 (convensional) and Model 2 (link). Seismic load used time history analysis. This time history analysis with three scaled reference seismic loads could describe lateral load acted on building.These structures to be evaluated by several parameters: base shear, inter-storey displacement, and structural performance level. The performance level analysis refers to ATC-40 which determined by ratio of maximum total roof displacement divided by structure height. The link model has higher period, less base shear, and higher displacement compared with the conventional one due to less stiffness of beam-column joint. The ratio of maximum drift divided by total structure height caused by four scaled reference seismic loads were less than 0.010 so the structural performance level was immediate occupancy.
\end{abstract}

Keywords: link, time history analisis, timber building, structural performance

\section{PENDAHULUAN}

Beberapa daerah di Indonesia yang termasuk dalam kategori rawan gempa antara lain Pulau Sulawesi. Pulau Sulawesi menjadi pertemuan tiga lempeng utama yang menimbulkan dampak geologi yang sangat kompleks dan beragam.

Fasilitas pendukung kepariwisataan di Indonesia juga harus menjanjikan, salah satunya adalah tempat penginapan atau hotel. Kota Makassar terdapat di Pulau Sulawesi, 
(ibu kota Provinsi), yaitu salah satu tujuan wisata di Indonesia. Seiring dengan hal itu maka bertumbuh banyak hotel. Walaupun Makassar merupakan wilayah yang relatif aman dari gempa berskala besar, tidak menutup kemungkinan bahwa pembangunan khususnya bangunan gedung di Makassar harus didesain terhadap beban gempa rencana.

Hotel yang berlokasi di Kota Makassar didesain menyerupai rumah panggung yang merupakan rumah khas bagi masyarakat Bugis-Makassar. Artinya, bangunan tersebut tidak secara langsung langsung berinteraksi dengan dengan tanah (terdapat kolom). Material struktur hotel panggung adalah kayu dengan jenis kayu Libung. Kayu dipilih sebagai bahan utama bangunan dengan pertimbangan fleksibel dan ringan.

Beban gempa dalam penelitian ini diperhitungkan menggunakan analisis riwayat waktu, yaitu menggunakan data rekaman gempa dan respons struktur dipelajari perilakunya. Dalam analisis, data gempa yang digunakan dapat berupa data rekaman asli maupun data rekaman gempa simulasi yang sudah diskalakan. Analisis riwayat waktu dapat mendeskripsikan perilaku struktur aktual dari bangunan selama gempa terjadi. Namun, data gempa sangat bervariasi, tergantung dari jenis tanah dari lokasi atau stasiun gempa itu direkam dan sejauh apa jarak antara lokasi terjadinya gempa dengan pusat gempa, sehingga dengan begitu akan lebih baik menggunakan beberapa data rekaman gempa.

Tujuan dari penelitian ini adalah melakukan studi kajian perilaku bangunan gedung kayu bertingkat rendah dengan analisis time history. Ruang lingkup penelitian ini mencakup evaluasi kinerja struktur bangunan kayu, yaitu sebagai berikut:

1. Struktur bangunan merupakan struktur bangunan kayu dengan luas bangunan 634,5 $\mathrm{m}^{2}$ dan dengan fungsi sebagai bangunan komersiil yaitu hotel. Perencanaan struktur bangunan kayu bertingkat hanya terbatas pada struktur atas;

2. Material yang digunakan adalah kayu dengan berat jenis $450 \mathrm{~kg} / \mathrm{m}^{3}$. Data sifat mekanika material kayu dan data kekakuan sambungan hubungan kolom-balok berdasarkan data sekunder dari tinjauan literatur penelitian Pranata dkk. (Pranata dkk., 2019);

3. Pemodelan struktur menggunakan bantuan perangkat lunak SAP2000 (CSI, 2020);

4. Acuan pembebanan dilakukan berdasarkan SNI 1727:2013 (SNI, 2013) yaitu Peraturan Pembebanan Indonesia untuk Gedung dan Bangunan Lain, beban yang digunakan meliputi beban hidup, beban mati, beban mati tambahan, dan beban gempa. Sedangkan acuan perencanaan ketahanan gempa berdasarkan SNI 1726:2012 
(SNI, 2012) yaitu Tata Cara Perencanaan Ketahanan Gempa untuk Struktur Bangunan Gedung dan Non Gedung;

5. Perhitungan beban gempa rencana dilakukan dengan pendekatan yaitu metode analisis time history. Data rekaman gempa yang diambil berjumlah tiga data, yaitu gempa yang memiliki PGA sebesar $0,120 \mathrm{~g}$ atau $117,72 \mathrm{~cm} / \mathrm{s} / \mathrm{s}$.

\section{METODE}

Penelitian ini melakukan studi kajian perilaku bangunan gedung kayu bertingkat rendah dengan analisis time history. Secara umum tahap-tahap yang akan dilakukan pada penelitian ini:

1. Studi pustaka adalah tahap pertama yaitu mempelajar teori dasar tentang definisi kayu, struktur bangunan kayu bertingkat, balok kayu, kolom kayu, kekakuan sambungan balok-kolom kayu, beban gempa dengan analisis riwayat waktu, gaya geser dasar, simpangan antar lantai, dan taraf kinerja struktur bangunan.

2. Tahap kedua adalah mendapatkan data-data mekanik kayu (data sekunder) yang dibutuhkan untuk pemodelan struktur dan penentuan parameter taraf kinerja. Pada tahap ini juga dilakukan kajian studi data sekunder perihal data kekakuan sambungan balok-kolom kayu, yang merupakan hasil dari pengujian beban siklik pada sambungan balok-kolom (Pranata, 2019).

3. Tahap ketiga adalah penentuan data-data pembebanan bangunan berdasarkan SNI 1727:2013 dan PPURB 1987, serta beban gempa yang didapat dari data rekaman gempa pada wilayah yang ditinjau, yaitu Kota Makassar. Pada tahap ini juga dipelajari dan diperhitungkan data-data rekaman gempa. Pemilihan ground motion design menggunakan data riwayat waktu dari lokasi yang diskalakan intensitasnya sesuai dengan target spektra lokasi tinjauan. Data rekaman gempa diperoleh dari website Cosmos Earthquake Data (Cosmos, 2019). Data rekaman gempa yang diambil berjumlah tiga data, yaitu gempa Chi-Chi, gempa Borrego Springs, dan gempa Chino Hills.

4. Tahap keempat adalah penentuan sistem struktur bangunan berdasarkan SNI 1726:2012, deskripsi struktur bangunan yang direncanakan, dilanjutkan dengan pemodelan struktur bangunan menggunakan software SAP2000. Pemodelan struktur bangunan dibagi menjadi dua, yaitu pemodelan konvensional (Model 1) dan pemodelan link (Model 2). Setelah dilakukan pemodelan beserta pendefinisian, dilakukan run analysis, lalu dilakukan pengecekan kapasitas pada elemen struktur kayu tersebut. 
5. Tahap kelima atau terakhir adalah evaluasi hasil analisis yaitu meliputi gaya geser, simpangan antar lantai, dan evaluasi taraf kinerja. Taraf kinerja struktur ditentukan dari rasio maximum total roof displacement terhadap ketinggian struktur.

Gambar 1 memperlihatkan data sekunder kurva kapasitas sambungan balokkolom kayu yang digunakan untuk pemodelan kekakuan sambungan pada pemodelan bangunan tipe 2, data diperoleh dari hasil pengujian oleh Pranata (Pranata, 2019). Gambar 2 memperlihatkan model benda uji untuk mendapatkan kurva beban vs deformasi lateral yang selanjutnya diinterpretasikan dalam bentuk kurva envelope (beban puncak tiap proses tahapan/siklus pengujian).

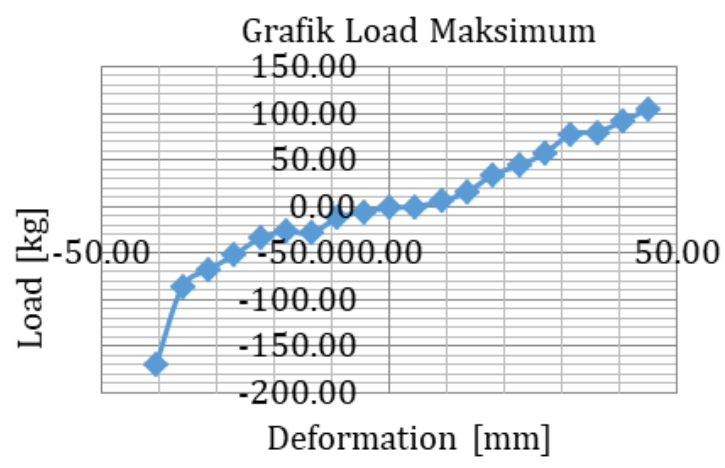

Gambar 1 Kurva Envelope Beban vs Deformasi Lateral Pengujian Sambungan BalokKolom Kayu Sumber: Pranata (2019)

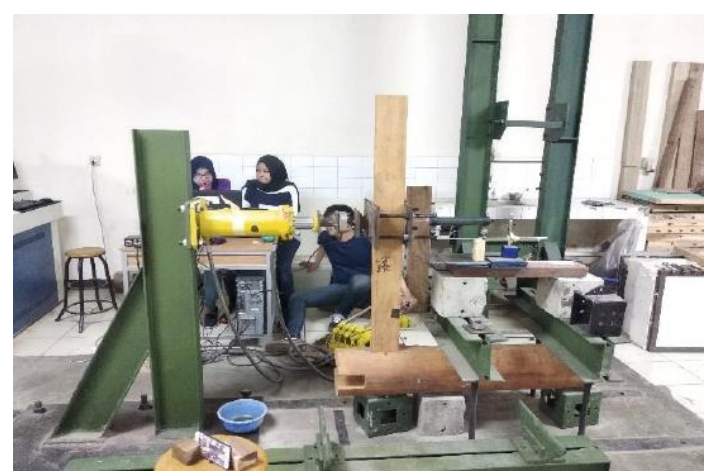

Gambar 2 Benda Uji Sambungan Parsial Balok-Kolom Kayu Sumber: Pranata (2019)

\section{STUDI KASUS DAN PEMBAHASAN}

Model struktur didefinisikan sebagai suatu perancangan struktur yang dibuat proposional agar dapat merepresentasikan bangunan aslinya baik dari segi ukuran 
maupun berbagai komponen lainnya yang dimanfaatkan untuk mengamati dan mengetahui perilaku struktur, respon struktur, dan kinerja struktur asli yang direncanakan.

Model struktur sebagai studi kasus penelitian adalah struktur kayu dengan material kayu yaitu kayu Libung. Sistem struktur yang digunakan dalam pemodelan struktur ini adalah sistem rangka yang terdiri dari elemen kolom, balok, dan pelat.

Bangunan yang dimodelkan terdiri dari dua model struktur, yaitu model struktur bangunan kayu konvensional (Model 1) tanpa memodelkan sambungan kolom-balok dan model struktur bangunan kayu dengan memodelkan sambungan kolom-balok (Model 2).

Kedua model struktur tersebut memiliki spesifikasi sebagai berikut:

1. bangunan yang berfungsi sebagai hotel terdiri dari tiga lantai termasuk atap;

2. material bahan yang digunakan adalah kayu;

3. mutu material kolom dan balok sama;

4. penampang balok berupa persegi dan penampang kolom berupa lingkaran;

5. luas Bangunan adalah $634,5 \mathrm{~m} 2$;

6. tinggi struktur lantai tipikal adalah $3 \mathrm{~m}$ dan tinggi lantai dasar adalah $4 \mathrm{~m}$;

7. dimensi kolom dimodelkan berdiameter lebih besar pada lantai satu;

8. dimensi balok induk dan balok anak dimodelkan tipikal setiap lantai;

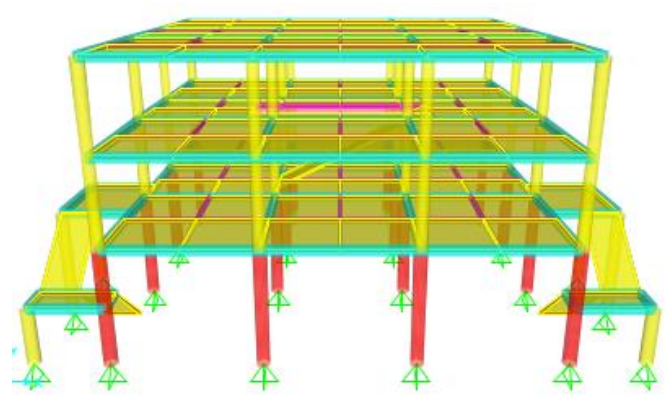

(a) Model 1

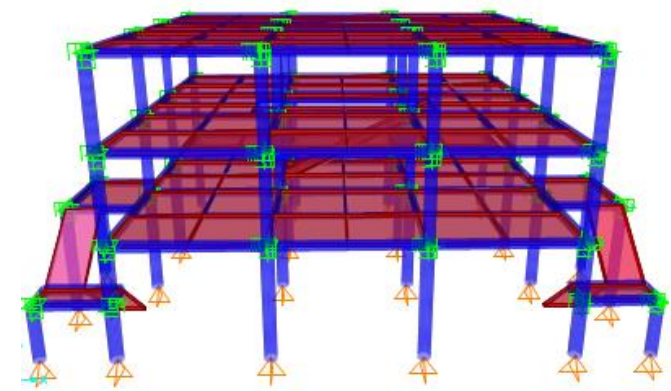

(b) Model 2

Gambar 3 Skematik Model 3D Bangunan Kayu Sumber: Rialita (2019)

Periode alami struktur Model 2 lebih besar daripada periode alami struktur Model 1, hal ini dikarenakan struktur Model 2 memiliki kekakuan sambungan yang lebih rendah, karena sambungan tidak sempurna jepit atau rigid. Pertimbangan ini dilakukan berdasarkan kondisi sambungan pada bangunan yang sebenarnya dimana terjadi potensi slip pada lubang kolom kayu khususnya pada sambungan tempat penempatan balok. Periode struktur Model 1 dan Model 2 dapat dilihat pada Tabel 1. 
Tabel 1 Periode Alami Struktur

\begin{tabular}{lcc}
\hline \multirow{2}{*}{ Model Struktur } & \multicolumn{2}{c}{ Periode Alami $\left(T_{C}\right)$} \\
\cline { 2 - 3 } & Arah X & Arah Y \\
\hline Model 1 & 0,757 & 0,692 \\
Model 2 & 0,862 & 0,825 \\
\hline Keterangan: & & \\
Model 1 & = struktur konvensional; \\
Model 2 = struktur link sambungan balok-kolom. \\
Sumber: Rialita (2019)
\end{tabular}

Gaya geser dinamik ( $V d)$ didapat dari hasil pengeluaran (output) software SAP2000 dengan menggunakan gempa arah X dan arah Y yang telah direncanakan. Besarnya gaya geser dinamik dasar $(V d)$ pada arah $\mathrm{X}$ dan arah $\mathrm{Y}$ pada tiap model serta perbandingan gaya geser dasar disampaikan pada Tabel 2, Tabel 3, dan Tabel 4.

Tabel 2 Gaya Geser Dasar (satuan kN) akibat Gempa Arah X

\begin{tabular}{cccccc}
\hline Gempa & Model 1 & Detik ke- & Model 2 & Detik ke- & Rasio [\%] \\
\hline G-S & 217,3 & & 215,0 & & 1,05 \\
G-CC & 259,7 & 99,9 & 224,9 & 122,8 & 27,30 \\
G-BS & 200,2 & 29,1 & 188,3 & 187,6 & 5,92 \\
G-CH & 112,5 & 28,4 & 118,7 & 29,5 & 3,19 \\
\hline
\end{tabular}

Sumber: Rialita (2019)

Tabel 3 Gaya Geser Dasar (satuan kN) akibat Gempa Arah Y

\begin{tabular}{cccccc}
\hline Gempa & Model 1 & Detik ke- & Model 2 & Detik ke- & Rasio [\%] \\
\hline G-S & 217,6 & & 215,5 & & 0,9 \\
G-CC & 227,1 & 94,1 & 212,5 & 56,8 & 3,8 \\
G-BS & 217,8 & 124 & 179,4 & 55,7 & 17,6 \\
G-CH & 122,5 & 17,8 & 109,4 & 27,8 & 10,7 \\
\hline
\end{tabular}

Sumber: Rialita (2019)

Dilihat dari Tabel 2 dan Tabel 3, bahwa gaya geser dasar struktur bangunan Model 1 memiliki nilai yang lebih besar daripada gaya geser dasar struktur bangunan Model 2. Secara umum struktur bangunan Model 2 memberikan gaya geser yang lebih kecil, artinya gaya gempa yang menimpa struktur bangunan tersebut lebih rendah daripada struktur bangunan Model 1. 
Tabel 4 Perbandingan Gaya Geser Dasar

\begin{tabular}{cccc}
\hline \multicolumn{3}{c}{ Perbandingan Gaya Geser Akibat Gempa Arah X [\%] } \\
\hline \multicolumn{2}{c}{ Struktur Model 1 } & \multicolumn{2}{c}{ Struktur Model 2 } \\
\hline G-S vs G-CC & 16,4 & G-S vs G-CC & 4,6 \\
G-S vs G-BS & 7,9 & G-S vs G-BS & 12,4 \\
G-S vs G-CH & 43,6 & G-S vs G-CH & 44,8 \\
\hline
\end{tabular}

\begin{tabular}{cccc}
\hline \multicolumn{2}{c}{ Perbandingan Gaya Geser Akibat Gempa Arah Y [\%] } \\
\hline \multicolumn{2}{c}{ Struktur Model 1 } & \multicolumn{2}{c}{ Struktur Model 2 } \\
\hline G-S vs G-CC & 4,4 & G-S vs G-CC & 1,4 \\
G-S vs G-BS & 0,1 & G-S vs G-BS & 16,8 \\
G-S vs G-CH & 43,7 & G-S vs G-CH & 49,3 \\
\hline
\end{tabular}

\footnotetext{
Keterangan:

Satuan Gaya Geser Dasar adalah kN.

G-S = Gempa Statik;

G-CC = Gempa Chi-Chi;

G-BS = Gempa Borrego Springs;

$\mathrm{G}-\mathrm{CH}=$ Gempa Chino Hills.

Sumber: Rialita (2019)
}

Perbandingan gaya geser dasar akibat gempa statik dan riwayat waktu gedung Model 1 dan Model 2 ditampilkan selengkapnya pada Tabel 4. Ada beberapa variasi persen perbandingan antara akibat gempa statik dan akibat gempa dengan analisis riwayat waktu, hal ini dikarenakan karakteristik ketiga gempa dengan analisis riwayat waktu yang berbeda-beda. Karakteristik gempa yang ditinjau adalah intensitas gaya bolak-balik gempa, frekuensi gempa, dan kerapatan getaran gempa.

Joint displacement didapat dari output pada SAP2000, sedangkan simpangan antar lantai akan didapatkan dengan perhitungan menggunakan persamaan berdasarkan SNI 1726:2012, yaitu sebagai berikut:

$$
\delta_{x}=\frac{c_{d} \delta_{x e}}{I_{E}}
$$

Keterangan:

$$
\begin{array}{ll}
C_{d} & =\text { faktor pembesaran defleksi; } \\
\delta_{x e} & =\text { defleksi pada lokasi yang ditinjau; } \\
I_{e} & =\text { faktor keutamaan. }
\end{array}
$$

Nilai simpangan antar lantai harus kurang dari simpangan antar lantai tingkat izin dan ditentukan berdasarkan SNI 1726:2012, yaitu sebagai berikut:

$$
\Delta \mathrm{a}=0,02 h_{S X}
$$

dengan $h_{S X}$ adalah tinggi total struktur. Hasil perhitungan simpangan antar lantai struktur dapat dilihat pada Gambar 4 dan Gambar 5. Perbandingan simpangan antar lantai untuk 
struktur Model 1 dan Model 2 dilihat pada Gambar 4 dan Gambar 5 sebagai berikut. Lantai 1 mempunyai elevasi $+4,0$ meter (tinggi lantai 4 meter), lantai 2 mempunyai elevasi $+7,0$ meter (tinggi lantai 3 meter), sedangkan atap mempunyai elevasi $+10,0$ meter (tinggi lantai atas 3 meter).

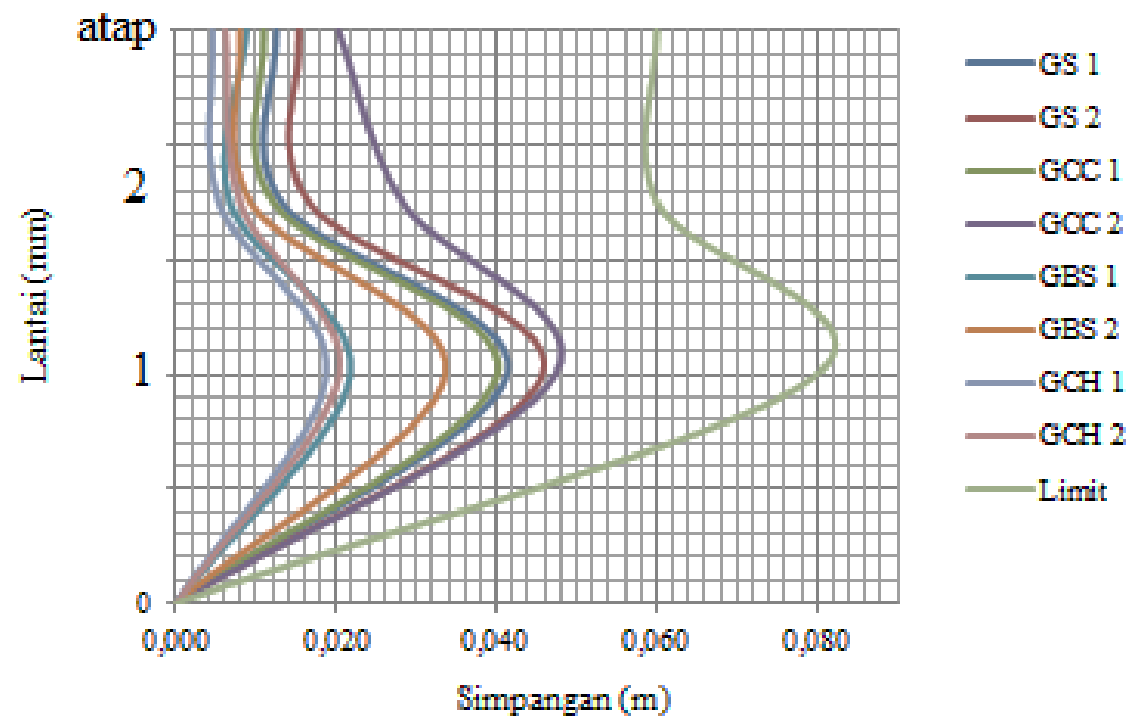

Keterangan:

GS = Gempa Statik GCC $=$ Chi-Chi; GBS = Borrego Springs; GCH = Chino Hills

Gambar 4 Perbandingan Drift Arah X

Sumber: Rialita (2019)

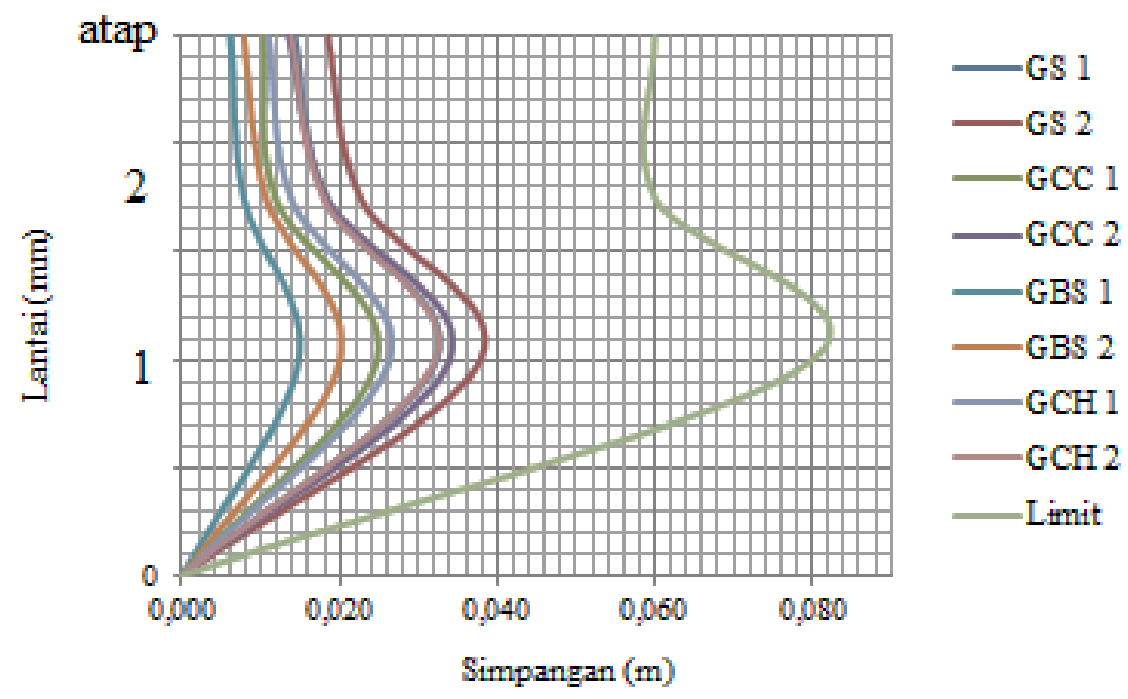

Keterangan:

GS = Gempa Statik; GCC = Chi-Chi; GBS = Borrego Springs; GCH = Chino Hills

Gambar 5 Perbandingan Drift Arah Y

Sumber: Rialita (2019) 
Gambar 4 dan Gambar 5 memperlihatkan bahwa simpangan ijin berdasarkan SNI 1726:2012 belum terlampaui, baik itu arah-X dan arah-Y, untuk seluruh pemodelan analisis struktur dengan berbagai rekaman gempa. Hal ini mengindikasikan bahwa deformasi yang terjadi masih memenuhi persyaratan ijin kekakuan bangunan gedung.

Simpangan antar lantai pada struktur Model 2 lebih besar daripada simpangan pada struktur Model 1, karena struktur Model 2 memiliki sambungan yang tidak kaku. Simpangan antar lantai yang dimiliki struktur bangunan Model 1 dan Model 2 akibat gempa statik dan gempa dengan analisis riwayat waktu adalah aman, karena nilai simpangan antar lantai (drift) di bawah nilai simpangan izin (drift limit).

Penentuan taraf kinerja atau level performance struktur berdasarkan ATC-40 akibat gempa statik dan gempa dengan analisis riwayat waktu meliputi gempa Chi-Chi, gempa Borrego Springs, dan gempa Chino Hills pada struktur bangunan Model 1 dan Model 2 selengkapnya ditampilkan pada Tabel 5 dan Tabel 6.

Tabel 5 Taraf Kinerja Struktur Model 1

\begin{tabular}{|c|c|c|c|c|}
\hline \multicolumn{5}{|c|}{ Taraf Kinerja Struktur Model 1} \\
\hline Beban Gempa & Arah Gempa & Maximum Total Drift $[\mathrm{mm}]$ & Rasio & Taraf Kinerja \\
\hline \multirow{2}{*}{ Statik } & $\mathrm{X}$ & 66,947 & 0,007 & $\mathrm{IO}$ \\
\hline & $\mathrm{Y}$ & 64,564 & 0,006 & $\mathrm{IO}$ \\
\hline \multirow{2}{*}{ Chi-Chi } & $\mathrm{X}$ & 63,201 & 0,006 & $\mathrm{IO}$ \\
\hline & $\mathrm{Y}$ & 46,865 & 0,005 & IO \\
\hline \multirow{2}{*}{ Borrego Springs } & $\mathrm{X}$ & 37,310 & 0,004 & $\mathrm{IO}$ \\
\hline & $\mathrm{Y}$ & 28,678 & 0,003 & $\mathrm{IO}$ \\
\hline \multirow{2}{*}{ Chino Hills } & $\mathrm{X}$ & 28,682 & 0,003 & $\mathrm{IO}$ \\
\hline & $\mathrm{Y}$ & 50,975 & 0,005 & $\mathrm{IO}$ \\
\hline
\end{tabular}

Sumber: Rialita (2019)

Tabel 6 Taraf Kinerja Struktur Model 2

\begin{tabular}{ccccc}
\hline \multicolumn{5}{c}{ Taraf Kinerja Struktur Model 2 } \\
\hline \multirow{2}{*}{ Beban Gempa } & Arah Gempa & Maximum Total Drift $[\mathrm{mm}]$ & Rasio & Taraf Kinerja \\
\hline \multirow{2}{*}{ Statik } & $\mathrm{X}$ & 77,700 & 0,008 & IO \\
& $\mathrm{Y}$ & 78,870 & 0,008 & IO \\
\hline \multirow{2}{*}{ Chi-Chi } & $\mathrm{X}$ & 95,915 & 0,010 & IO \\
& $\mathrm{Y}$ & 65,809 & 0,007 & IO \\
\hline \multirow{2}{*}{ Borrego Springs } & $\mathrm{X}$ & 50,954 & 0,005 & IO \\
& $\mathrm{Y}$ & 38,409 & 0,004 & IO \\
\hline \multirow{2}{*}{ Chino Hills } & $\mathrm{X}$ & 30,528 & 0,003 & IO \\
& $\mathrm{Y}$ & 63,827 & 0,006 & IO \\
\hline
\end{tabular}

Sumber: Rialita (2019)

Hasil dari perhitungan yang ditampilkan pada Tabel 5 dan Tabel 6, bahwa secara umum nilai maksimum total drift struktur Model 1 lebih besar daripada nilai maksimum total drift struktur Model 2. Secara umum taraf kinerja pada keempat jenis beban gempa dan pada kedua model struktur adalah immadiate occupancy. 
Taraf kinerja immadiate occupancy menunjukkan struktur bangunan aman. Risiko korban jiwa dari kegagalan struktur rendah, komponen struktural khususnya balok dan kolom tidak mengalami kerusakan berat, sehingga bangunan tetap dapat berfungsi dan beroperasi kembali.

\section{SIMPULAN}

Penelitian mengenai studi kajian perilaku bangunan gedung kayu bertingkat rendah dengan analisis time history menghasilkan simpulan sebagai berikut:

1. Secara umum model struktur dengan link memiliki nilai periode lebih besar daripada struktur model konvensional, hal ini dikarenakan model struktur dengan link memiliki kekakuan sambunganyang lebih rendah.

2. Secara umum nilai rasio maximum drift terhadap tinggi total struktur akibat empat gempa yang ditinjau memiliki nilai rasio lebih kecil 0,010 yang artinya dengan nilai rasio tersebut taraf kinerja struktur adalah immadiate occupancy.

3. Keuntungan model struktur dengan link adalah gaya geser dasar akibat gempa lebih rendah, tetapi kerugian model struktur dengan link adalah simpangannya lebih besar karena stuktur tersebut memiliki sambungan balok-kolom yang tidak kaku.

4. Analisis riwayat waktu dengan beban gempa referensi yang diskalakan dapat digunakan untuk memberikan gambaran gaya lateral yang mengenai bangunan, dimana dalam penelitian ini ternyata lebih tinggi dibandingkan akibat gempa statik.

\section{DAFTAR PUSTAKA}

1. Athari (2017), Analisis Performance Dermaga Berdasarkan Metode Displacement Based Design, Institut Teknologi Bandung.

2. Awaludin, A. (2019), Rumah Kayu Negeri Sakura [diakses 23 Januari 2019]. Tersedia pada https://awaludin.staff.ugm.ac.id/rumah-kayu-negeri-sakura/.

3. Azhary (2014), Desain dan Analisis Perilaku Struktur Bangunan Tabung Berangka yang Menerima Beban Gempa. Indonesia, Institut Teknologi Bandung.

4. Bayyinah, Faimun (2017), Studi Perbandingan Analisis Respon Spektra dan Time History untuk Desain Gedung, Jurnal Teknik ITS, Volume 6.

5. Computer and Structures Inc. (2010), SAP2000 User Guide, Computer and Structures Inc., 1995 University Ave., Berkeley, CA 94704, USA. 
6. Cosmos Earthquake Data. [akses 06 Februari 2019]. Tersedia pada website: http://www.strongmotioncenter.org/vdc/scripts/default.plx.

7. Monika (2016), Kekuatan Geser Panel Kayu Vertikal dengan Perkuatan Single Bracing Tulangan Baja Akibat Pembebanan Siklik, Jurnal Ilmiah Semesta Teknika, Volume 19.

8. Pranata, Y.A., Suryoatmono, B. (2019), Struktur Kayu Analisis dan Desain dengan LRFD, Penerbit Remaja Rosdakarya, Bandung.

5. Pranata, Y.A., Suryoatmono, B. (2014), Kekuatan Tekan Sejajar Serat dan Tegak Lurus Serat Kayu Ulin (Eusideroxylon Zwageri). Jurnal Teknik Sipil Institut Teknologi Bandung, Volume 21.

6. Pranata, Y.A., Frisda, T., Tobing, H.L. (2018), Pengujian Parsial Material Kayu Struktur Rumah Adat Tradisional Nias.

7. Pranata, Y.A., Frisda, T., Tobing, H.L. (2019), Pengujian Sambungan Join Balok-Kolom Kayu Rumah Tradisional Nias. Standar Nasional Indonesia 1726 (2012), Tata Cara Perencanaan Ketahanan Gempa untuk Struktur Bangunan Gedung dan Non Gedung, Badan Standardisasi Nasional.

8. Rendra, Kurniawandy, Djauhari (2015), Kinerja Struktur Akibat Beban Gempa dengan Metode Respon Spektrum dan Time History Studi Kasus: Hotel SKA Pekanbaru), Jurnal JOM FTEKNIK, Volume 2.

9. Rialita, S.N. 2019. Kinerja Struktur Bangunan Kayu Bertingkat Akibat Beban Gempa Dengan Analisis Riwayat Waktu, Tugas Akhir (tidak dipublikasikan), Program Studi Teknik Sipil, Fakultas Teknik dan Perencanaan, Institut Teknologi Nasional, Bandung.

10. Rinaldi, E. 2019. Pengenalan SAP2000. [akses 26 Februari 2019]. Tersedia pada https://www.slideshare.net/elpanrinaldi/pengenalan-sap-2000.

11. Standar Nasional Indonesia 1727 (2013), Beban Desain Minimum dan Kriteria Terkait untuk Bangunan Gedung dan Struktur Lain, Badan Standardisasi Nasional.

12. Standar Nasional Indonesia 7973 (2013), Spesifikasi Desain untuk Konstruksi Kayu, Badan Standardisasi Nasional. 